\title{
Liberdade é filha do conhecimento?
}

Nico Stehr

Tradução de Joana Canêdo

N um artigo recenteda N ew York Review of Books (18 denovembro de2004, p. 38), o biólogo molecular Richard Lewontin afirma que "o conhecimento exigido para a racionalidade política, outrora disponível para as massas, está agora em poder de uma elite especial mente educada, uma situação que cria uma série de tensões e contradições na operação da democracia representativa". 0 otimismo compartilhado pelos filósofos do Iluminismo francês - em particular a visão de Condorcet sobre o papel do conhecimento para suplantar a pobreza, a violência e a ignorância, e também para criar uma sociedade democrática sustentável - se teria, portanto, extinguido? (cf. Jones, 2004, pp. 16-63).

$\mathrm{N}$ a mesma linha, $\mathrm{H}$ arry Kroto, o químico inglês ganhador do prêmio N obel, numa coluna publicadano Guardian (22 demaio de2007, Education 1-2), denuncia o governo do Reino U nido por estar arruinando a ciênciabritânica ea educação científica do país. E isso a despeito da "necessidade, [que] nuncafoi maior, deuma população geral capaz deter uma compreensão satisfatória de ciência etecnologia". K roto, que agora pesquisa eleciona nos Estados U nidos e não mais na Inglaterra, acrescenta que "vivemos num mundo econômica, social eculturalmentedependentedeciênciaquenão apenasfuncionebem, masquetambém seja aplicada de maneira inteligente".

Além disso, considerando a crescente especial ização da produção do conhecimento científico, como observa Immanuel Wallerstein (2004, p. 8), 
para citar um cientista social, a mai oria dos indivíduos é desprovida da "capacidade deapreciação crítica individual racional, seja sobre a qualidade das evidências ou sobre a solidez do raciocínio teórico aplicado na análise dos dados. Q uanto 'mais difícil' for a ciência, mais verdadeira ela é".

Richard Lewontin, $\mathrm{H}$ arry K roto el mmanuel Wallerstein discutem com ceticismo o uso crescente do conhecimento contemporâneo - em especial 0 das ciências naturais, não apenas por governos, mas também como um instrumento político (cf. Pielke, 2007) -, que não leva em conta o quanto cidadãos comuns são visivelmente privados da habilidade de entender de forma racional o discurso da ciência e da tecnologia modernas. Essa é uma síntese conveniente das questões sobre as múltiplas conexões entre conhecimento e democracia que pretendo explorar neste artigo. Seria de fato 0 caso de não podermos escapar do dilema de outorgar nossa apreciação crítica a comunidades auto-selecionadas de experts?

0 que vemos é que as questões sobre as relações entre detenção do conhecimento e democracia não são discutidas de maneira ampla e direta nas ciências sociais contemporâneas. No entanto, se ampliarmos nossa perspectiva para as relações mediadas entre o conhecimento, a economia, a sociedade civil e os regimes democráticos, constantemente encontraremos pistas dessa discussão, como por exemplo capital cultural eliberdade política, acesso a instituições escolares e distribuição social do conhecimento, competitividade das nações, identidades sociais e inclusão política, para mencionar apenas algumas questões na agenda das ciências sociais e da política de hoje.

Começarei com um conjunto relativamente amplo de questões eafirmações. Como M ax H orkheimer enfatizou - em contraste com K arl M arx -, justiça, ou equidade, e liberdade não se sustentam mutuamente. Isso também se aplicaria à relação entre democracia e conhecimento? 0 u o conhecimento seria democratizador? 0 progresso do conhecimento, em especial seus avanços rápidos, seria um ônus para a democracia, a sociedade civil ea capacidade do indivíduo de afirmar sua própria vontade? Sehá uma contradição entre conhecimento e processos democráticos, isso seria uma novidade moderna? $\mathrm{O}$ u 0 avanço das democracias liberais seria co-determinado pela união das forças do conhecimento eda conduta política democrática, 0 que permite afirmar que a sociedade civil, senão a democracia, é filha do conhecimento? 


\section{Panorama}

Para dar continuidade à minha exploração das múlti plas conexões entre sociedade civil, governança e democracia, seguirei uma série de passos: indagarei se essas conexões são co-determinadas por uma crescente viabilização do conhecimento por parte de atores modernos - enfatizando as possibilidades cada vez maiores de cooperação recíproca em organizações da sociedade civil e movimentos sociais, e, talvez, a influência também crescente de amplos segmentos da sociedade em regimes democráticos por meio do aprimoramento dessa capacidade dos atores de viabilizar conhecimento. 0 acesso ao conhecimento e seu controle são sem dúvida estratificados. Porém, além da com freqüência subestimada detenção de conhecimento de muitos cidadãos envolvidos em assuntos públicos, existe ainda o papel crescente do conhecimento científico como capacidade para ação em política.

Inicialmente, explorarei alguns limites e obstáculos ao acesso ao conhecimento, indagando: 1) é possível reconciliar expertise e sociedade civil?, 2) é concebível conciliar sociedade civil e conhecimento como um bem privado?, e 3) até que ponto a discussão sobre o papel da experti se e do conhecimento como um bem privado se aplica ao caso das ciências sociais e das humanidades? As ciências sociais e as humanidades são fontes viabilizadoras de conhecimento na sociedade contemporânea? Elas estão criando novas capacidades para ação ao oferecer orientações tanto inovadoras como práticas para políticas públicas?

Cada um dos termos centrais que introduzi neste breve panorama éum conceito essencialmente contestado, cujos significados dão margem a infindáveis debates (cf. G allie, 1955-1956). Procurarei portanto esclarecer como pretendo usar esses conceitos, especialmente a noção de conhecimento em geral ea de viabilização do conhecimento em particular.

\section{Os termos}

Conhecimento pode ser definido como uma capacidade para ação. 0 uso do termo "conhecimento" como uma capacidade para ação é derivado da famosa observação deFrancis Bacon de que conhecimento époder (scientia est potentia). Bacon sugere que o conhecimento deriva sua utilidade da capacidade de pôr al guma coisa em movimento. Considero que a ciência não apenas se esforça para compreender o mundo, no sentido de desenvolver 
modelos da realidade, mas também, num sentido prático, está interessada em como realizar coisas, tornando-se assim um modelo para a realidade.

Refiro-me à sociedade civil não no sentido tradicional, como uma sociedade política ou um Estado, mas como a arena de cidadãos ativos interposta entre o Estado e as formas íntimas da vida.

A detenção do conhecimento melhora a agência (a capacidade de agir). A agência está no cerne da sociedade civil. Ela é a habilidade que os cidadãos têm para definir objetivos, desenvolver compromissos, perseguir valores e ter sucesso ao realizá-los. $D$ ar o devido valor à agência éa essência do governo subsidiário ou do autogoverno.

Ao indagar sobre o controle diversificado do conhecimento por atores em sociedades modernas, estou aplicando o problema do acesso diferenciado ao conhecimento à questão do controle sobre sua própria vida graças ao recurso do conhecimento.

Introdução

Existe certamente um grande número de hipóteses mais ou menos antagônicas relacionadas com as razões para a emergência e a persistência de regimes democráticos e a força das sociedades civis dentro de tais sistemas sociais. Por exemplo, Francis Fukuyama (apud Grove, 2003) explica sua tese sobre o fim das ideologias concorrentes do século passado enfatizando que "existem imperativos econômicos e políticos fundamentais conduzindo a história numa direção, no sentido de uma maior democracia". No entanto, outros pesquisadores argumentam que democracias podem estabelecer-se em países pobres, onde não acompanham, portanto, o desenvolvimento econômico. $E$, como as al egações para a guerra no I raque mostraram, presume-se também que a democracia suceda aos tiros de canhão.

Em contraste com essas considerações modernas, John Stuart M ill, em Thespirit of the age (1831), publicado no retorno à Inglaterra, após uma estadia na França, afirma sua convicção de que as real izações intel ectuais de sua época tornam o progresso social inevitável. $\mathrm{N}$ o entanto, o progresso visando à melhoria das condições sociais não é, argumenta $\mathrm{M}$ ill, o resultado de um "aumento do saber" ou das realizações coletivas da ciência. Estáligado, mais do queisso, a uma difusão geral do conhecimento.

O bservando as transformações morais e políticas da metade do século XIX, M ill predizquea maior possi bilidadedeescolha individual ea emancipação dos "costumes" resultarão numa ampla difusão do conhecimento eda 
educação. Essetema repercutefortementena estrutura social quehojeemergeà medida que a sociedade industrial dálugar à soci edade do conheci mento.

John Stuart M ill era um grande admirador do estudo clássico de Alexis deTocquevillesobre a sociedadeamericana. Com efeito, M ill escreveu uma resenha da D emocracia na América (1835-1840), publicada quase ao mesmo tempo que 0 seu The spirit of the age. No entanto, existem diferenças decisivas entre M ill e Tocqueville em suas concepções sobre a democracia, em particular no que se refere ao papel do conhecimento dos cidadãos para e em regimes democráticos.

Tocqueville encerra seu estudo da sociedade americana com a observação de que o sucesso educacional de seus cidadãos é uma força influente para a manutenção da democracia na América. Enquanto M ills tem uma confiança considerável na capacidade independente deiluminação - considerando a educação, o conhecimento e as habilidades intelectuais como condições necessárias para a força dos regimes democráticos - , Tocqueville vê o conhecimento como uma condição suficiente para a democracia.

D a concepção de M ill, segue-se que intelectuais e cientistas desempenharão um papel político significativo nas democracias. No caso de Tocqueville, é o cidadão comum, o público esclarecido e sua prática política imediata, que dá força aos sistemas políticos democráticos, confrontando o poder político. Sem tomar partido sobre as especificidades da disputa entre Tocqueville e M ill, tendo a concordar com suas ênfases no papel social que a distribuição do conhecimento desempenha na sociedade civil e na democracia'.

Rejeito, portanto, a teoria da microfísica do poder, tal como foi elaborada por Foucault. Como se sabe, em seu trabalho genealógico, Foucault descreve a modelagem unidimensional do indivíduo pelas disciplinas científicas - tais como a penologia e a psicanálise - e pelo enorme poder de disciplinamento e medição microgerenciado nas grandes instituições sociais. As observações de Foucault sobre "a destruição do sujeito" são baseadas numa visão que confere um poder excessivo às agências que distribuem conhecimento. 0 conhecimento, tal como foi descrito em Arqueologia do saber, é um discurso anônimo que exerce controle sobre indivíduos desprovidos de poder ${ }^{2}$. Foucault, assim, subestima a maleabilidade do conhecimento, o quanto o conhecimento pode ser contestado, e a capacidade dos indivíduos e das organizações da sociedade civil de propagar o conhecimento de maneira a resistir, opor e refrear a opressão que pode ser exercida pelas grandes instituições sociais na sociedade moderna.
1.É preciso assinalar que Jean-Jacques Rousseau, ThomasH obbese Karl M arxnão compartilham essaasserção positiva do papel do conhecimento (científico) na racionalização da ação política eno aperfeiçoamento da democracia, eaindamenosno queserefereàfelicidade ou ao controle das paixões humanas.

2. A afirmação de Foucault sobre $a$ afinidade entre os detentores do poder eo conhecimento tem uma semelhança familiar com a tese de que 0 aumento do capital humano coletivo, aindaque "façacrescer ahabilidadedaspessoas de resistir à opressão", também "fazcrescer osbenefíciosdoscomandantesdesubjugálos" (Barro, 1999, p. S159). 
Diversos impedimentos sociais afetam a ampla disseminação do conhecimento na sociedadee, portanto, obstruem o papel efetivo que ele desempenha numa democracia. Farei referência a algumas dessas barreiras nas seguintes questões: 1) é possível reconciliar democracia e expertise? e 2) é possível reconciliar democracia e conhecimento como propriedade?

Reconciliando democracia e expertise

Como vimos, muitos observadores estão convencidos de que a distância existente entre os agentes poderosos que detêm habilidades especial izadas e o conhecimento dos leigos ampliou-se dramática e irreversivelmente no período recente. Por outro lado, éevidente que a deferência social, o respeito que não se põe em dúvida e a autoridade incontestada em relação ao conhecimento dos grandes profissionais (professores, médicos, advogados) vêm declinando, ao menos na sociedade ocidental, desde pelo menos a década de 1960.

Contudo, há ainda um apoio difundido à perspectiva "cientificista" no que se refere à natureza do modelo iluminista, qual seja, que o conhecimento é universal e universalmente útil, e que existe um fluxo de mão única do conhecimento que vai dos experts ao público leigo.

Com o ritmo acelerado de chegada de novas informações, torna-se aparente uma separação cada vez maior entre aqueles que participam diretamente do processo de produção do conhecimento e o público leigo. À me dida que a esfera mais ampla do público é excluída, a assimetria entre 0 conhecimento especializado e o público passa a ser vista como tendo conseqüências graves para a natureza da sociedade civil.

D escreverei o modelo iluminista, ou da escassez, em mais detal hes. A facilidade com a qual delegamos ao que os economistas chamam de "princípios", isto é, à apreciação de experts (fora de nossa própria especialidade, é claro), parece ter ficado mais acentuada em todas as instituições sociais modernas, enão apenas na ciência. Ao mesmo tempo, no campo do "entendimento público da ciência", considera-se que o analfabetismo científico reduz as capacidades democráticas dos cidadãos, incluindo a possibilidade de uma governança democrática da ciência.

Amplos segmentos do público tornaram-se desprovidos de um envolvimento efetivo nos processos democráticos. 0 exercício da cidadania hoje requer um nível cada vez maior de letramento científico. Essa perda de contato com a ciência e essa deferência epistêmica não são apenaso resultado da 
crescente distância cognitiva entre a ciência e o saber cotidiano. Elas são afetadas também pela velocidade sempre crescente da expansão do conhecimento mediante uma divisão cada vez maior do trabal ho na ciência (poucos recursos cognitivos no próprio campo da ciência) e pela utilização do conhecimento numa capacidade produtiva.

A redução da proximidade cognitiva aumenta a distância política em relação à ciência, por exemplo, ao restringir a reflexão pública quanto às transformações das realidades sociais e culturais (antecipadas ou não) que resultariam da aplicação do novo conhecimento. A comunidade científica tem sua parte de responsabilidade nessa diminuição da proximidade intelectual, já que a auto-imagem preferida da ciência, como um empreendimento consensual, embora monolítico e monológico, éconflitante tanto com seu papel público como com suas próprias lutas internas no que diz respeito às prioridades de pesquisa, incluindo a geração de dados e sua interpretação.

Contudo, tanto no terreno político como no moral, muitos grupos, associações e instituições devem ser consultados antes que decisões sejam tomadas sobre questões que afetam a regulamentação do novo conhecimento e, portanto, afetam indiretamente o desenvolvimento da ciência e da tecnologia. Seria enganoso pensar que a perda de contato e o considerável analfabetismo científico encontrados nas sociedades modernas sejam de certa forma um "defeito potencialmente fatal na autoconcepção das pessoas de hoje" (como sugere $\mathrm{G}$ erald $\mathrm{H}$ olton), e/ ou sinal da possibilidade de um colapso dramático do apoio público à ciência.

É mais acurado falar deum estado de equilíbrio instável afetando a autonomia e a dependência da ciência na sociedade moderna. A perda de um contato intelectual próximo entre ciência e público é perfeitamente compatível tanto com um apoio difuso à ciência na sociedade moderna quanto com uma ênfase sobre os esforços legais e políticos para controlar o impacto da ciência e da tecnologia.

Por outro lado, porém, a perda de contato cognitivo é quase irrelevante quando "contato" se refere à proximidade cognitiva como prérequisito para participação pública em decisões que afetam o conhecimento científico e tecnológico. Tal afirmação é desprovida de sentido na prática, pois parece exigir um engajamento do público na ciência em progresso.

Para estabelecer um julgamento sobre expertise e sociedade civil, precisamos levar em consideração contextos específicos. Com efeito, a "solução" para o papel social do conhecimento e da democracia na socieda- 
de moderna não exige uma resposta geral, mas respostas apropriadas a cada caso (cf. Bohman, 1999, p. 190).

As condições nas quais grupos divergentes compreendem o conhecimento especializado variam consideravelmente. Por exemplo, vivemos em uma era na qual a ciência e a tecnologia "não gozam mais da estima incontestada que detiveram por dois séculos como as mais autênticas formas de verdade - para muitos as únicas formas autênticas de verdade" (Wallerstein, 2004, p. 7). Assim, em vez de tratar a relação entre expertise e público como uma série de eventos determinados envolvendo atores individuais e isolados, devemos pensar nessa interação como sendo mediada por identidades culturais e concepções variáveis dos ben efícios sociais da ciência e da tecnologia. A engenhosidade com a qual organizações da sociedade civil reconstroem a ciência ea tecnologia tão distintamente é afetada por circunstâncias políticas e econômicas contingentes.

N uma era de políticas do saber, que se esforça para regulamentar e disciplinar os novos conhecimentos e artefatos técnicos, não faz mais sentido ver o público como ingenuamente resistente a novas capacidades para agir, mas, ao contrário, é preciso vê-lo como prudente, incerto e curioso sobre as possíveis conseqüências das novas informações (cf. Stehr, 2005). I novações que têm por base a ciência e a tecnologia são julgadas pela sociedade civil em contraste com suas visões de mundo, preferências, valores e crenças. Basta tomar a pesquisa de célula-tronco, a medicina genética ou os alimentos geneticamente modificados como exemplos. Em suma, no contexto do conhecimento, da política e do discurso público sobre autorizar capacidades inovadoras para agir, a balança de poder está agora pendendo para 0 lado da sociedade civil, em detrimento da ciência.

Todavia, sem algum elemento de confiança impessoal (cf. Shapiro, 1987) exibido por pessoas comuns em relação aos experts, a expertise desapareceria. 0 s experts de hoje estão constantemente envolvidos num número notável de controvérsias. 0 crescente campo das políticas públicas, que estabelece limitações à presença de certos ingredientes nos produtos al imentícios, regulamentações de segurança, gerenciamento de risco, vigilância e controle de riscos, teve o efeito colateral de arruinar a reputação dos experts. Enquanto alguma questão permanece em discussão, em especial nos casos de matérias publicamente contenciosas, o poder e a influência dos experts e contra-experts ficam limitados. Porém, uma vez que uma decisão é tomada e o assunto é encerrado, a autoridade dos experts se torna incontestada. 
Para a comunidade científica, a falta de proximidade cognitiva em relação ao público geral tem tanto vantagens como desvantagens. A separação entre a ciência e o público pode tal vez explicar, pelo menos em parte, por que a comunidade científica, em vista de sua utilidade para as corporações, para as forças armadas e para o governo, tem sido capaz de preservar um nível considerável de autonomia intelectual. Tal autonomia é, no entanto, contingente de uma série de fatores internos e externos à comunidade científica. Ela assinala um desprendimento simbólico e uma independência que podem ser traduzidos como recursos positivos para 0 Estado e outras agências sociais. A ciência pode se tornar uma voz autoritária nas matérias de políticas públicas e representar a abertura da sociedade em relação a lutas ideológicas e materiais com outros sistemas políticos. No entanto, a distância cognitiva limita a efetividade imediata da "voz da ciência" tanto nas organizações da sociedade civil como nas questões de política pública. A independência da ciência pode também resultar numa celebração excessiva da atividade científica "normal" e conduzir a uma falta de inovação.

Reconciliando democracia e conhecimento como propriedade

Testemunhando diante do Congresso dos Estados Unidos há mais de um século, John Powell, um pioneiro no campo das ciências naturais, tocou em uma das mais intrigantes características do conhecimento, qual seja, "a posse da propriedade é exclusiva; a posse do conhecimento não é exclusiva". A despeito da tese de Powell, al gumas formas de conhecimento são exclusivas e se tornam bens privados como resultado de restrições le gais, tais como as patentes ou as leis de copyright.

Q ue o conhecimento seja tratado como um bem público ou privado tem importantes conseqüências. Por exemplo, o conhecimento novo, ou incremental, costuma ser muito mais protegido. No contexto de sistemas econômicos, e também em ciência, isso cria um sério dilema. A base de crescimento do conhecimento é conhecimento. Se o conhecimento é protegido, o crescimento do conhecimento é impedido. No entanto, se o conhecimento não é protegido, argumentam os economistas, o incentivo para investir em novo conhecimento desaparece; monopólios são essenciais para 0 avanço do conhecimento e das invenções.

Em contraste com o conhecimento incremental, o estoque de saber geral mundano erotinizado consiste principalmente em saber não-rival enão- 
excludente; ou seja, esse tipo de conhecimento pode muito bem constituir bens públicos.

0 conhecimento científico constitui uma das mais importantes condições para a modernização, no sentido de uma extensão e uma ampliação persistentes da ação social e econômica que a ciência, enão qual quer sistema social moderno, gera.

$N$ ão desejo discutir a questão contenciosa sobre vantagens e desvantagens que poderiam existir entre designar direitos de propriedade do conhecimento versus o ganho no contexto do bem-estar geral da sociedade; ou as compensações resultantes de tratar o conhecimento como um bem público em oposição à perda de receita para aqueles que não podem colher os benefícios de suas inven ções e descobertas.

Economistas, acadêmicos do direito e importantes organizações internacionais, como o Banco M undial, defendem queo conhecimento deve ser um bem público (global). D e um ponto de vista econômico, isso significa que ele deveria perder as características típicas dos bens econômicos, tais como a concorrência e a exclusão. 0 fato de al gumas formas de conhecimento serem bens públicos é um empecilho à defesa de que conhecimento adicional é necessário. No entanto, é esse novo conhecimento que se torna lucro.

Assim, o velho dilema relativo à propriedade - se ela gera poder, moldando assim as relações humanas, ou se o contrário é verdade - persiste até mesmo nas sociedades do conhecimento.

0 discurso sobrea relação entre conhecimento científico e democraciaé centrado na ciência, quer ele seja sobre o papel dos experts, quer seja sobre a idéia contestada de que conhecimento é propriedade. A discussão concentrou-se até aqui exclusivamente no papel social do conhecimento técnico ou das ciências naturais. N as notas finais deste texto, gostaria de focar, ao contrário, nas ciências sociais: em suas reivindicações a propósito do conhecimento e em seu impacto na sociedade moderna.

Viabilizando conhecimento?

Podem ser identificados dois modelos para lidar com as afirmações do conhecimento científico geradas pelas ciências sociais e pelas humanidades. Aquele que ressoa com boa parte da discussão precedente, e afirma a existência de uma forte variação do conhecimento entre ciência e sociedade, é o model o instrumental. A ciência fala com a sociedadee o faz com um suces- 
so considerável, enquanto a sociedade tem pouca oportunidade, se é que alguma, de responder. Em suma, usando o modelo instrumental como padrão, o conhecimento das ciências sociais em si é o responsável por seu sucesso (ou fracasso) social. M ais especificamente, o modelo instrumental estipula que a utilidade prática associada às ciências sociais está conectada apenas à "cientificidade" sólida de tal conhecimento.

A abordagem alternativa para as trajetórias sociais é o modelo de capacidade. Esse modelo enfatiza a influência social das ciências sociais e das humanidades como um processo motivado pelo impacto das idé as na socie dade. As ciências sociais e as humanidades são essencialmente vistas como produtoras de significados.

As ciências sociais, mesmo se consideradas como uma grande, se não crescente, reserva de significados que se difundem na sociedade, não têm 0 monopólio dos recursos intelectuais. Em contraste com o modelo instrumental, o modelo de capacidade enfatiza que os agentes que "empregam" o conhecimento das ciências sociais são agentes ativos, que transformam, relançam ou redesenham o conhecimento de suas disciplinas. Esse atributo fala contra ao "cientificização social" direta das visões de mundo e dos significados mundanos no discurso moderno das ciências sociais.

0 modelo de capacidade estipula que o conhecimento social científico é um recurso intelectual possivelmente aberto e complexo e, assim, pode ser modelado ao longo da "viagem" que parte da comunidade das ciências sociais para a sociedade. Esse modelo assume ainda que nem a produção nem a aplicação desse conhecimento envolve reprodução idêntica. 0 modelo de capacidade é portanto associado à possi bilidade das pessoas de aplicar criticamente o conhecimento das ciências sociais usando recursos locais de conhecimento e fazer assim com que as ciências sociais tenham de se explicar em relação ao público.

Notas finais

M inha discussão concentrou-se nas questões que dizem respeito a como adquirir conhecimento na sociedade moderna, mais do que ao que fazer com ele. Esse é o tópico para outro artigo. A asserção básica por ora, no entanto, é que a evolução das sociedades modernas para sociedades do conhecimento conduz cada vez mais à democratização e à negociação das asserções do conhecimento. Estamos nos movendo vagarosamente de uma situação de domínio dos experts para uma forma muito mais ampla, com- 
partilhada, de governança das asserções do conhecimento (cf. Stehr, 2005; Leighninger, 2006).

Minha hipótese é não apenas que o conhecimento científico é mais maleável e acessível do que vem sendo sugerido pela perspectiva clássica, como a do "modelo iluminista" (cf. Irwin, 1999) das relações entre ciência e sociedade, mas que a nova sociologia do conhecimento científico criou a perspectiva de que a produção do conhecimento científico éde muitas formas bastante semelhante a outras práticas sociais. Asfronteiras entre expertise e saber cotidiano são muito menos delimitadas e muito mais robustas do que se supõe, especialmente nas observações que deploram a distância crescente entre conhecimento especializado e conhecimento do público.

Além disso, o queconta não éque agora podemos saber o suficiente, mas quepodemossaber demais. A negociação social denossas novas capacidades para o conhecimento não é tão dependente do conhecimento técnico e especializado das ciências naturais quanto do conhecimento viabilizador ge rado pelas ciências sociais eas humanidades. 0 acesso geral ao conhecimento viabilizador produzido nas ciências sociais para a sociedade civil enfrenta menos obstáculos do que nas ciências naturais. A detenção do conhecimento ganhou uma externalidade social mediantea produção de uma democracia, ou cidadania, mais participativa, que ben eficia principalmente as organizações da sociedade civil. Tudo isso produz desafios particulares não apenas em termos do acesso ao conhecimento das ciências sociais, mas também naformadenovosmodos departicipação. É nesse ponto queas organizações da sociedade civil serão desafiadas.

Espaço social paraa comunicação entre ciência/ciências sociaise público já existe. A possi bilidade de negociação democrática e de prática científica deve ser vista como parte de um empreendimento e de um contexto social mais amplos, nos quais tanto cientistas profissionais, como expertse público leigo participam do diálogo. A ciência é uma força social eficiente porque pode, ao mesmo tempo, engajar as instituições eas organizações da sociedadecivil, e contar com elas. 0 s casos de ativismo contra a mudança climática eaAID S são exemplos ricos de processos sociaisnos quais as fronteiras entre experts e público leigo são bastante maleáveis (cf. Bohman, 1999).

Finalmente, não deveríamos ser severos demais quanto à falta de fundamento científico em muitos dos temas que tratamos como conhecimento na vida comum, porque tendemosa nos dar bastantebem com esse tipo de conhecimento, na maioria das vezes, pelo menos (cf. Schutz, 1946; H ardin, 2003, p. 5). 


\section{Referências Bibliográficas}

Barro, Robert. (1999), "The determinants of democracy”. Journal of Political Economy, 107: S158-S183.

Boн m AN, James. (1999), "C itizenship and norms of publicity: wide public reason in cosmopolitan societies". Political Theory, 27: 176-202.

Gallie, W. B. (1955-1956), "Essentially contested concepts". Proceedings of the Aristotelian Society N ew Series, 56: 167-198.

Grove, M ichael. (2003), "W hy I fear today's brave new world". TheT imes, 16 maio. H ARDIN , Russell J. (2003), "If it rained knowledge". Philosophy of the Social Sciences, 33: 3-24.

Irwin, Alan. (1999), "Science and citizenship". In: Scanlon, Eileen et al. (eds.), Communicating science: contexts and channels. 1aㅡ edição 1995. Reader 2. Londres, Routledge.

Jones, Gareth Stedman. (2004), An end to poverty? A historical debate. N ova York, Columbia University Press.

LEIGH NIN GER, M att. (2006), T henext form of democracy: how expert rule is giving way to shared governance and why politics will vever be the same. N ashville, Tennessee, Vanderbilt U niversity Press.

Pielke, Roger A., Jr. (2007), The honest proker: making sense of science in policy and politics. Cambridge, Cambridge U niversity Press.

Schutz, Alfred. (1946), "The well-informed citizen". Social Research, 13: 463-478.

Shapiro, Susan. (1987), "The social control of personal trust". American Journal of Sociology, 93: 623-658.

Stehr, Nico. (2005), Knowledge politics: governing the consequences of science and technology. Boulder, Colorado, Paradigm Publishers.

W allerstein, Immanuel. (2004), The uncertainties of knowledge. Philadelphia, Pennsylvania, Temple U niversity Press.

\section{Resumo}

Liberdade é filha do conhecimento?

0 tema que exploro neste artigo concerne às múltiplas conexões entre conhecimento, sociedade civil, governança e democracia. Poderia situar esse conjunto geral de questões no contexto de como tais con exões se estabelecem: se são ou não co-determinadas por uma capacidade dos atores modernos de viabilizar o conhecimento. Assim, enfatizaria as possi bilidades crescentes de cooperação recíproca em organizações da sociedade civil e movimentos sociais, e a influência cada vez maior de amplos segmentos da sociedade em regimes democráticos. Porém meu objetivo específico tem de ser mais 
modesto. 0 acesso ao conhecimento e o seu controle são estratificados. Explorarei três barreiras e obstáculos ao acesso ao conhecimento, indagando: 1) é possível reconciliar expertise e sociedade civil?; 2) é concebível reconciliar sociedade civil e conhecimento como um bem privado?; e, finalmente, 3 ) as ciências sociais e as humanidades são fontes viabilizadoras do conhecimento?

Palavras-chave: Conhecimento; Poder; Expertise; Sociedade civil; Sociedade do conhecimento; D emocracia.

\begin{abstract}
Is freedom the child of knowledge?

The theme explored in this paper concerns the multiple linkages between knowledge, civil society, governance and democracy. I could place this general set of questions within the context of whether or not they are co-determined by the enabling knowledgeability of modern actors and stress the growing possibilities for reflexive cooperation among civil society organizations and social movements, as well as the increasing influence of broad sectors of society in democratic regimes. H owever my specific objective is necessarily more modest. Access to knowledge and its control are stratified. I shall explore three barriers and hurdles to the access to knowledge and ask: (1) can expertise and civil society be reconciled? (2) is it conceivable to reconcile civil society and knowledge as a form of private property? (3) and finally, are the social sciences and humanities a source for enabling knowledge?

Keywords: Knowledge; Power; Expertise; C ivil Society; KnowledgeSociety; D emocracy.
\end{abstract}

Texto recebido em 18/ $7 / 2007$ eaprovado em 28/2/2008.

$\mathrm{N}$ ico Stehr é professor titular da cadeira Karl M annheim deEstudos Culturais da Zeppelin University e membro do Kulturwissenschaftliches Institut, Alema nha. E-mail: nico.stehr @t-online.de. 